ARTICLE

\title{
Hydride-based antiperovskites with soft anionic sublattices as fast alkali ionic conductors
}

\author{
Shenghan Gao ${ }^{1,6}$, Thibault Broux ${ }^{1,6}$, Susumu Fujii (1) ${ }^{2,6}$, Cédric Tassel (1) ${ }^{1 凶}$, Kentaro Yamamoto ${ }^{3}$, Yao Xiao $^{3}$, \\ Itaru Oikawa4 ${ }^{4}$ Hitoshi Takamura (1) 4, Hiroki Ubukata1, Yuki Watanabe1, Kotaro Fujii i ${ }^{5}$, \\ Masatomo Yashima (i] ${ }^{5}$, Akihide Kuwabara (10 ${ }^{2}$, Yoshiharu Uchimoto (i] ${ }^{3}$ \& Hiroshi Kageyama (1) ${ }^{1 \times}$
}

\begin{abstract}
Most solid-state materials are composed of p-block anions, only in recent years the introduction of hydride anions $\left(1 \mathrm{~s}^{2}\right)$ in oxides (e.g., $\mathrm{SrVO}_{2} \mathrm{H}, \mathrm{BaTi}(\mathrm{O}, \mathrm{H})_{3}$ ) has allowed the discovery of various interesting properties. Here we exploit the large polarizability of hydride anions $\left(\mathrm{H}^{-}\right)$together with chalcogenide $\left(\mathrm{Ch}^{2-}\right)$ anions to construct a family of antiperovskites with soft anionic sublattices. The $\mathrm{M}_{3} \mathrm{HCh}$ antiperovskites $(\mathrm{M}=\mathrm{Li}, \mathrm{Na})$ adopt the ideal cubic structure except orthorhombic $\mathrm{Na}_{3} \mathrm{HS}$, despite the large variation in sizes of $\mathrm{M}$ and $\mathrm{Ch}$. This unconventional robustness of cubic phase mainly originates from the large size-flexibility of the $\mathrm{H}^{-}$anion. Theoretical and experimental studies reveal low migration barriers for $\mathrm{Li}^{+} / \mathrm{Na}^{+}$ transport and high ionic conductivity, possibly promoted by a soft phonon mode associated with the rotational motion of $\mathrm{HM}_{6}$ octahedra in their cubic forms. Aliovalent substitution to create vacancies has further enhanced ionic conductivities of this series of antiperovskites, resulting in $\mathrm{Na}_{2.9} \mathrm{H}\left(\mathrm{Se}_{0.9} \mathrm{l}_{0.1}\right)$ achieving a high conductivity of $\sim 1 \times 10^{-4} \mathrm{~S} / \mathrm{cm}\left(100^{\circ} \mathrm{C}\right)$.
\end{abstract}

\footnotetext{
${ }^{1}$ Department of Energy and Hydrocarbon Chemistry, Graduate School of Engineering, Kyoto University, Nishikyo-ku, Kyoto 615-8510, Japan. ${ }^{2}$ Nanostructures Research Laboratory, Japan Fine Ceramics Center, Nagoya 456-8587, Japan. ${ }^{3}$ Graduate School of Human and Environmental Studies, Kyoto University, Sakyo-ku, Kyoto 606-8501, Japan. ${ }^{4}$ Department of Materials Science, Graduate School of Engineering, Tohoku University, Sendai 980-8579, Japan.

${ }^{5}$ Department of Chemistry, School of Science, Tokyo Institute of Technology, 2-12-1-W4-17 O-okayama, Meguro-ku, Tokyo 152-8551, Japan. ${ }^{6}$ These authors

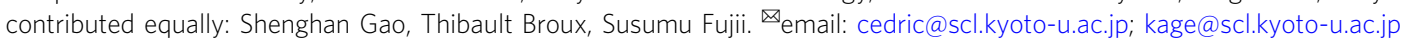


erovskites with a formula of $\mathrm{ABX}_{3}$ (A, B: cations, $\mathrm{X}$ : anions) are ubiquitous and central to electronics, photonics, and energy technologies ${ }^{1,2}$. Their electronically inverted analogs, antiperovskites, are playing an increasingly major role in solid-state chemistry and physics owing to their various intriguing properties, such as giant magnetoresistance in $\mathrm{Mn}_{3} \mathrm{GaC}^{3}$, superconductivity in $\mathrm{Ni}_{3} \mathrm{MgC}^{4}$, negative thermal expansion in $\mathrm{Mn}_{3} \mathrm{BA}(\mathrm{B}=\mathrm{Zn} \text {, } \mathrm{Cu} \text { etc.; } \mathrm{A}=\mathrm{N}, \mathrm{C})^{5,6}$, efficient water splitting electrocatalytic activity in $\mathrm{Ni}_{3} \mathrm{FeN}^{7}$, superionic conductivity in $\mathrm{Ag}_{3} \mathrm{SI}^{8}$ and large capacity in $\left(\mathrm{Li}_{2} \mathrm{Fe}\right) \mathrm{OCh}(\mathrm{Ch}=\mathrm{S}, \mathrm{Se}, \mathrm{Te})$ as lithium battery cathodes ${ }^{9}$.

In particular, lithium-rich and sodium-rich antiperovskites (LiRAPs and NaRAPs), for example, $\mathrm{M}_{3} \mathrm{OCl}, \mathrm{M}_{3} \mathrm{OBr}(\mathrm{M}=\mathrm{Li}$, $\mathrm{Na}$ ), and $\mathrm{Na}_{3} \mathrm{OBH}_{4}$, have recently attracted a great deal of attention as they exhibit a high lithium (or sodium) ionic conductivity and are thus regarded as promising solid-state electrolytes enabling high-energy-density lithium metal batteries ${ }^{10-13}$. Similar to the $\mathrm{F}^{-}$superionic conductivity in $\mathrm{NaMgF}_{3}$ perovskite ${ }^{14}$, the antiperovskite $\mathrm{M}_{3} \mathrm{OCl}$ allows $\mathrm{Li}^{+} / \mathrm{Na}^{+}$superionic conductivity benefited from the M-rich content $\left(60 \text { at } \% \text { in } \mathrm{Li}_{3} \mathrm{OCl}\right)^{10,13}$. Another advantage of antiperovskite is its extraordinary chemical diversity. Similar to perovskite, a variety of combinations of elements can be accommodated, while maintaining the simple structural topology, thereby offering an ideal situation to easily and fully characterize fast ionic transport ${ }^{15,16}$. A very recent study on $\mathrm{Li}_{3} \mathrm{OCl}$ indicated that the presence of hydroxide $\left(\mathrm{OH}^{-}\right)$, providing the composition of $\mathrm{Li}_{3-x} \mathrm{O}_{1-x}(\mathrm{OH})_{x} \mathrm{Cl}$, or ultimately $\mathrm{Li}_{2}(\mathrm{OH}) \mathrm{Cl}^{17}$.

In the search of new fast ion-conducting solid-state materials ${ }^{18-27}$, a great deal of effort has been made to understand ionic transport in Li-ion conductors, where two features of the anion-host matrix have been highlighted ${ }^{18-20}$. The first feature proposed by Ceder et al. is that the anion arrangement of bodycentered cubic (bcc) provides the lowest migration barrier for Li-ion diffusion, rather than a close-packed (fcc or hcp) anion framework ${ }^{27}$. Antiperovskites host the bcc framework composed of A- and B-site anions ${ }^{10,13,16}$. The second feature is that polarizable anions can critically soften and flatten the cationic transport landscape, leading to lower activation energy and higher ionic conductivity $23,25,28-31$. In fact, thiophosphate ionic conductors, such as $\mathrm{Li}_{10} \mathrm{GeP}_{2} \mathrm{~S}_{12}$ with the highest Li-ion conductivity, are believed to benefit from a soft and polarizable anion lattice ${ }^{32}$.

In this study, we present the synthesis of a series of LiRAPs and NaRAPs, $\mathrm{M}_{3} \mathrm{HCh}(\mathrm{M}=\mathrm{Li}, \mathrm{Na}$; $\mathrm{Ch}=\mathrm{S}, \mathrm{Se}, \mathrm{Te})$ with both anionic sites occupied by soft and polarizable anions of $\mathrm{H}^{-}$and $\mathrm{Ch}^{2-}$ (Fig. 1) ${ }^{33,34}$. To our knowledge, LiRAPs and NaRAPs have been obtained only with oxide/hydroxide anions at the $B$ site, which considerably limits the scope of structures and properties. Experimental and theoretical investigations have revealed that the occupation of highly polarizable and size-flexible $\mathrm{H}^{-}$ anions at the $\mathrm{B}$ site in $\mathrm{M}_{3} \mathrm{HCh}$ introduces several interesting features, including the stability and robustness of the ideal cubic structure and softening of phonon mode associated with $\mathrm{HM}_{6}$ octahedral rotation, which could be advantageous for realizing high $\mathrm{Li}^{+} / \mathrm{Na}^{+}$conductivity. The energy migration barriers based on vacancy and interstitial dumbbell mechanisms are found to be lower than those of oxide-based LiRAPs and NaRAPs. $\mathrm{Li}^{+} / \mathrm{Na}^{+}$vacancy creation via iodine $\left(\mathrm{I}^{-}\right)$doping (for $\mathrm{Ch}^{2-}$ ) is a potential strategy to increase the ionic conductivity of this series of antiperovskites, where I-doped cubic $\mathrm{Na}_{3} \mathrm{HSe}$ with formula $\mathrm{Na}_{2.9} \mathrm{H}\left(\mathrm{Se}_{0.9} \mathrm{I}_{0.1}\right)$ delivers a high total $\mathrm{Na}^{+}$ conductivity exceeding $1 \times 10^{-4} \mathrm{~S} / \mathrm{cm}$ at $100^{\circ} \mathrm{C}$ with a low bulk activation energy of $\sim 0.18 \mathrm{eV}$ in agreement with the calculated one $(\sim 0.16 \mathrm{eV})$.
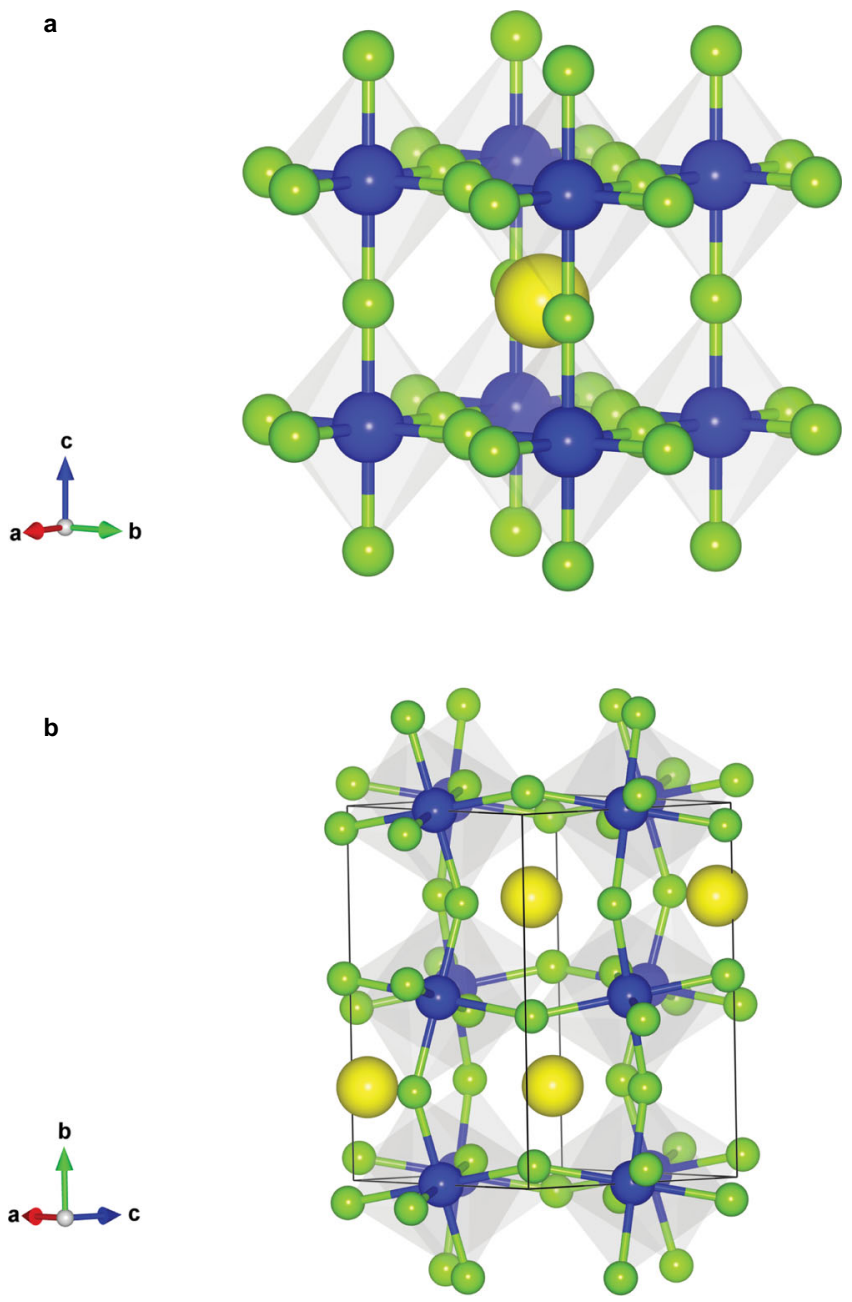

Fig. 1 Crystal structure of hydride-based $\mathbf{M}_{\mathbf{3}} \mathbf{H C h}$ antiperovskite $(\mathbf{M}=\mathbf{L i}$, Na). a Crystal structure of the cubic antiperovskite (space group $P m-3 \mathrm{~m}$ ). In this study, we obtained $\mathrm{Li}_{3} \mathrm{HCh}(\mathrm{Ch}=\mathrm{S}, \mathrm{Se}, \mathrm{Te})$ and $\mathrm{Na}_{3} \mathrm{HCh}(\mathrm{Ch}=\mathrm{Se}$, $\mathrm{Te}$ ), where $\mathrm{H}^{-}$anion (blue; $\mathrm{B}$ site) is bonded with $\mathrm{Li}^{+} / \mathrm{Na}^{+}$cations (green) forming $\mathrm{HLi}_{6} / \mathrm{HNa}_{6}$ octahedron, while chalcogenide anion (yellow; A site) sits in cuboctahedral coordination site. As opposed to conventional perovskites, the cubic structure is robust in a wide range of compositions. b The orthorhombic anti-GdFeO 3 type (space group Pnma) $\mathrm{Na}_{3} \mathrm{HS}$ with $\mathrm{HNa}_{6}$ octahedral tilting.

\section{Results}

Structure determination. The high-resolution synchrotron X-ray diffraction (SXRD) pattern of the sample prepared using $\mathrm{LiH}$ and $\mathrm{Li}_{2} \mathrm{~S}$ at $5 \mathrm{GPa}$ and $700{ }^{\circ} \mathrm{C}$ (Fig. 2a) shows the formation of a highly crystalline compound, along with impurity phases that could be identified as $\mathrm{LiH}, \mathrm{Li}_{2} \mathrm{~S}$, and $\mathrm{BN}$ (insulating high-pressure sleeve). The diffraction profile of the main phase was indexed in a cubic system with the lattice parameter of $a=3.85189$ (6) $\AA$ (see Supplementary Fig. 1), which is comparable to those of reported antiperovskite oxyhalides $\mathrm{Li}_{3} \mathrm{OCl}$ and $\mathrm{Li}_{3} \mathrm{OBr}(a=3.900 \AA$ and $3.989 \AA$, respectively) with the space group $P m-3 m^{10,12}$.

Given the known antiperovskites, e.g., $\mathrm{Ag}_{3} \mathrm{SI}^{8}, \mathrm{Li}_{3} \mathrm{OCl}^{10}$, with a smaller anion at the octahedral $\mathrm{B}$ site and a larger one at the cuboctahedral A site, we performed Rietveld refinement assuming $\mathrm{S}^{2-}$ at the $1 b(1 / 2,1 / 2,1 / 2)$ Wyckoff position and $\mathrm{H}^{-}$at the $1 a(0$, $0,0)$ site and $\mathrm{Li}^{+}$at the $3 d(1 / 2,0,0)$ site within the space group of $P m-3 m$, corresponding to a stoichiometric $\mathrm{Li}_{3} \mathrm{HS}$ formula. The Rietveld refinement converged successfully with values of 

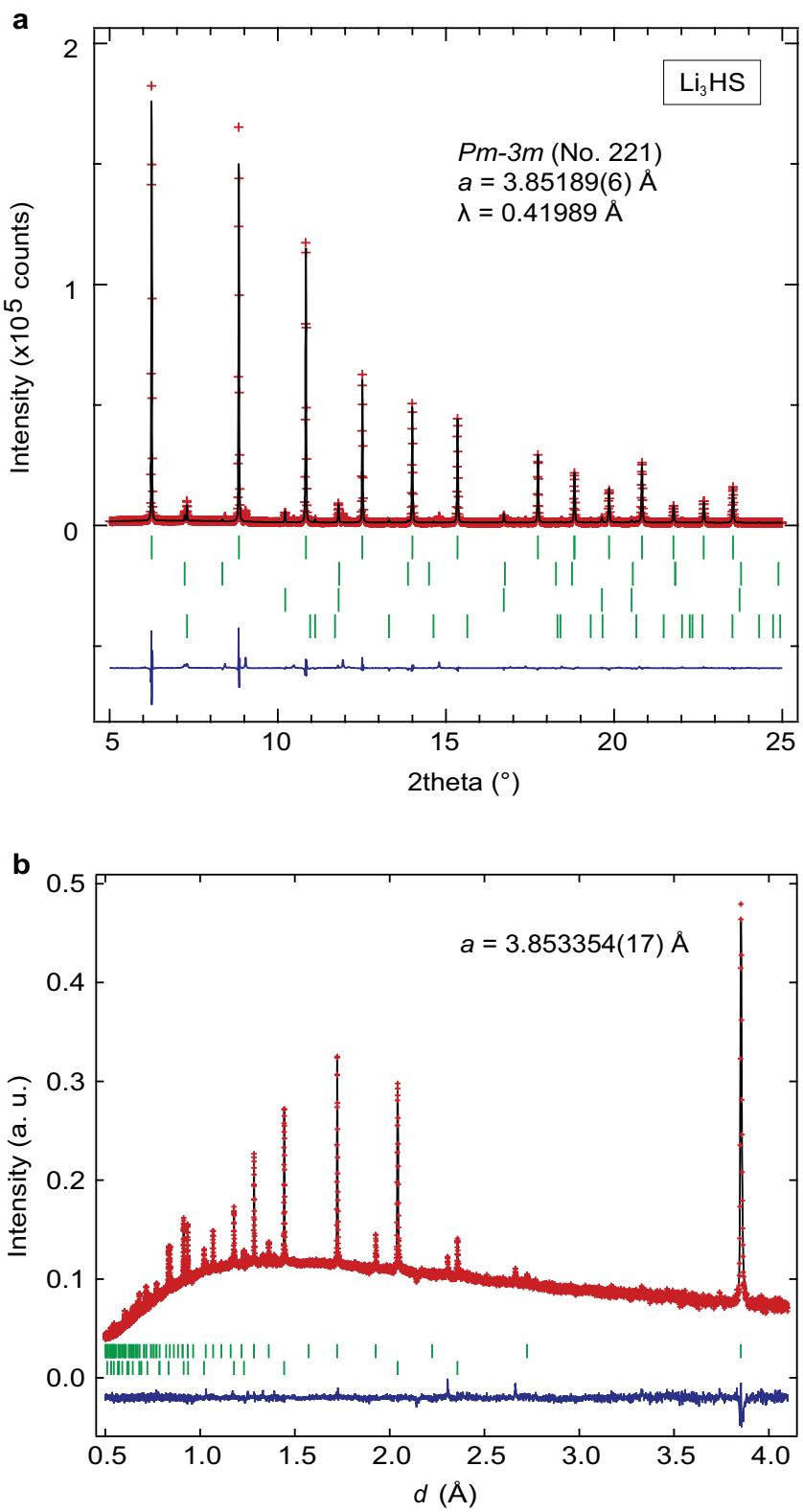

Fig. 2 Structural determination of $\mathbf{L i}_{3} \mathbf{H S}$. Rietveld refinement of a SXRD and $\mathbf{b}$ ND. The red crosses, black solid line, blue solid line, and green dashes denote, respectively, the observed, calculated, difference intensities, and calculated Bragg reflections (from top to bottom: $\mathrm{Li}_{3} \mathrm{HS}, \mathrm{Li}_{2} \mathrm{~S}, \mathrm{LiH}, \mathrm{BN}$ in a; $\mathrm{Li}_{3} \mathrm{HS}, \mathrm{LiH}$ in b).

$R_{\text {Bragg }}=4.28 \%$ and $R_{\mathrm{f}}=2.87 \%$ (see Fig. 2a and Supplementary Table 1). Swapping the anionic octahedral B site and cubocathedral A site to give a $\mathrm{Li}_{3} \mathrm{SH}$ led to poor refinement values of $R_{\text {Bragg }}=22.6 \%$ and $R_{\mathrm{f}}=11.2 \%$ (Supplementary Fig. 2).

Subsequently, time-of-flight powder neutron diffraction (ND) data were analyzed to better characterize lighter elements of $\mathrm{H}$ and Li. The presence of hydrogen in the sample can be readily seen from Fig. $2 \mathrm{~b}$ exhibiting a high background intensity. The neutron refinement assuming the $\mathrm{Li}_{3} \mathrm{HS}$ structure yielded $R_{\mathrm{wp}}=1.35 \%$ and $R_{\text {Bragg }}=6.28 \%$ thus confirming this structural model. Details of the refinement are listed in Supplementary Table 1. It is found that the $\mathrm{Li}^{+}, \mathrm{H}^{-}$, and $\mathrm{S}^{2-}$ ions fully occupy their respective crystallographic sites, confirming the stoichiometric composition. We also examined the possibility of antisite disorder between $\mathrm{H}^{-}$and $\mathrm{S}^{2-}$; the Rietveld refinement allowing intersite anion exchange
(Supplementary Table 1) in the stoichiometric composition led to the full occupancy $(g)$ of $\mathrm{H}^{-}$at the B site $\left(g_{\mathrm{B}}(\mathrm{H})=1.015(5)\right)$ with $R_{\mathrm{wp}}=1.37 \%$ and $R_{\mathrm{Bragg}}=6.64 \%$, which implies that the anions are perfectly ordered. Note that $\mathrm{Pd}_{3} \mathrm{H}_{0.89}$ In also has hydrogen at the octahedral site ${ }^{35}$, but this material may not be classified as hydride, given the metallic nature of this material and the nearly identical electronegativity between $\mathrm{H}(2.2)$ and $\mathrm{Pd}(2.2)^{33}$. Attempts to synthesize $\mathrm{Li}_{3} \mathrm{HS}$ compound at a lower pressure $\left(1 \mathrm{GPa} / 3 \mathrm{GPa} ; 700^{\circ} \mathrm{C}\right)$ or under ambient pressure $\left(700{ }^{\circ} \mathrm{C}\right.$ for $12 \mathrm{~h}$ ) using $\mathrm{LiH}$ and $\mathrm{Li}_{2} \mathrm{~S}$ was unsuccessful (Supplementary Fig. 3), indicating the high-pressure metastability of this antiperovskite.

Materials variety. To our knowledge, $\mathrm{Li}_{3} \mathrm{HS}$ is the first LiRAP with hydride anions at the B site. Next, we attempted to extend the antiperovskite family by including sodium as well as other chalcogenides under high-pressure and high-temperature reactions. The XRD patterns of $\mathrm{Li}_{3} \mathrm{HSe}$ and $\mathrm{Li}_{3} \mathrm{HTe}$ (Supplementary Fig. 4) are similar to $\mathrm{Li}_{3} \mathrm{HS}$, with Bragg reflections moving toward lower angles, as expected from increasing ionic radii of chalcogenide anions. The obtained cell parameters of the cubic unit cell are 3.9744(5) $\AA$ for $\mathrm{Li}_{3} \mathrm{HSe}$ and 4.2221(3) $\AA$ for $\mathrm{Li}_{3} \mathrm{HTe}$. Regarding the sodium system, the SXRD profiles of $\mathrm{Na}_{3} \mathrm{HSe}$ (Supplementary Fig. 5) and $\mathrm{Na}_{3} \mathrm{HTe}$ (Supplementary Fig. 6) are compatible with the cubic symmetry $(P m-3 m)$ with $a=4.55901$ (7) $\AA$ and $a=4.76349(2) \AA$, respectively. The larger cell parameters result from the difference in the cationic size $\left(\mathrm{Na}^{+}: 1.02 \AA\right.$ vs. $\left.\mathrm{Li}^{+}: 0.76 \AA\right)^{36}$. Rietveld refinements of $\mathrm{Na}_{3} \mathrm{HSe}$ and $\mathrm{Na}_{3} \mathrm{HTe}$ validated the cubic antiperovskite structure, with detailed structural information in Supplementary Tables 2 and 3.

To gain microscopic information on the crystal structure, we conducted ${ }^{23} \mathrm{Na}$ nuclear magnetic resonance (NMR) with/without magic-angle spinning (MAS) for $\mathrm{Na}_{3} \mathrm{HSe}$. The spectra in Supplementary Fig. 7 were fitted as a second-order quadrupolar line shape of the central transition with a common set of $C_{Q}=$ $1.61 \mathrm{MHz}$ and $\eta=0.04$, where $C_{Q}$, and $\eta$ denote a quadrupole coupling constant and an asymmetry parameter, respectively. The ${ }^{23} \mathrm{Na}$ MAS NMR spectrum shows a single sharp peak at 24.2 ppm, which indicates that all sodium atoms are in the same environment, in accordance with the refinement result that no significant chemical disorder occurs in $\mathrm{Na}_{3} \mathrm{HSe}$ (Supplementary Fig. 5 and Supplementary Table 2). This isotropic chemical shift (i.e., $24.2 \mathrm{ppm}$ ) is fairly consistent with that derived from DFT calculation (20.4 ppm with $C_{Q}=1.95 \mathrm{MHz}$ and $\left.\eta \mathrm{DFT}=0\right)$.

In the case of $\mathrm{Na}_{3} \mathrm{HS}$, the XRD pattern (Supplementary Fig. 4) is clearly different and indexed by an orthorhombic unit cell ( $a=$ 6.76037(9) $\AA, b=8.89761(10) \AA$, and $c=6.28659(8) \AA$ ), which is related to the pristine cubic cell by $\sqrt{2} a_{\mathrm{p}} \times 2 b_{\mathrm{p}} \times \sqrt{2} c_{\mathrm{p}}$. This supercell and the extinct reflections suggest that $\mathrm{Na}_{3} \mathrm{HS}$ adopts an anti-GdFeO ${ }_{3}$ structure (Pnma space group, Fig. 1b), as previously reported for $\mathrm{M}_{3} \mathrm{OA}(\mathrm{M}=\mathrm{Sr}, \mathrm{Eu}, \mathrm{Ba} \text {, and } \mathrm{A}=\mathrm{Si}, \mathrm{Ge})^{37}$. SXRD (Supplementary Fig. 8) and ND (Supplementary Fig. 9) data were refined assuming the anti- $\mathrm{GdFeO}_{3}$ structure, yielding reasonable parameters, as listed in Supplementary Tables 4 and 5.

As shown in Fig. 3a, the normalized (cubic) lattice parameters of the LiRAP and NaRAP series both show linear dependence as a function of the chalcogen ionic radii, with approximately the same slope. As it is commonly done for normal perovskite structures, the tolerance factor $(t)$ was estimated for our system, assuming the hydride ionic radius of $1.40 \AA^{36,38}$. We found that the cubic structures are observed over a wide range $0.85<t<0.97$ (Supplementary Table 6), in sharp contrast to perovskite oxides where slight deviations from unity readily lead to structural distortions. It is also noticed that oxide-based antiperovskites $\mathrm{M}_{3} \mathrm{OA}(\mathrm{M}=\mathrm{Ca}, \mathrm{Sr}, \mathrm{Ba}, \mathrm{Eu} ; \mathrm{A}=\mathrm{Si}, \mathrm{Ge}, \mathrm{Sn}, \mathrm{Pb})$ exhibit octahedral tilting when $t<0.97^{37}$, implying that our hydride-based system is 
a

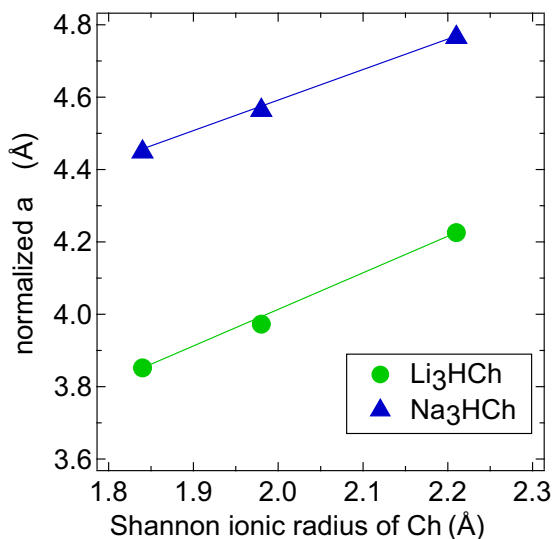

C

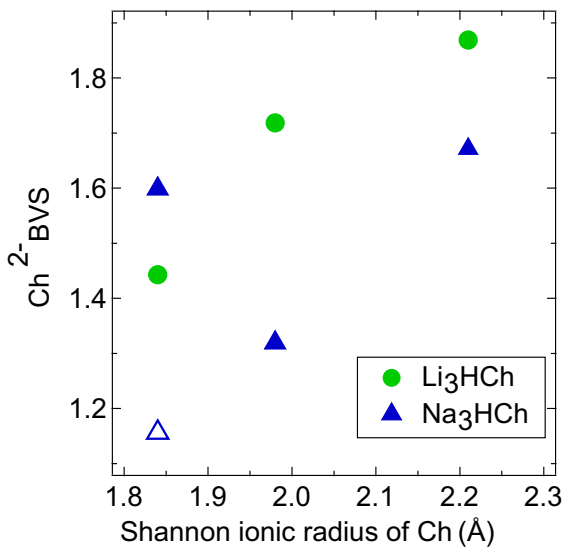

b

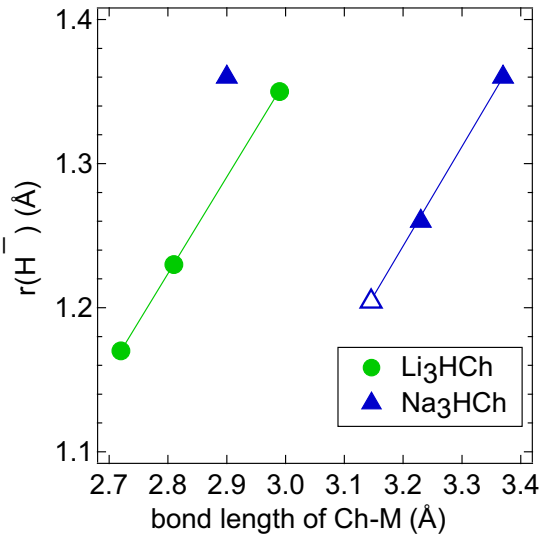

d

variation in bond length of $B-M(\AA)$

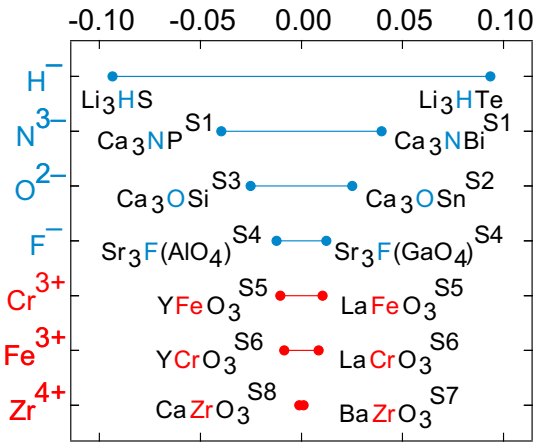

Fig. 3 Structural features of $\mathbf{M}_{\mathbf{3}} \mathbf{H C h}$ antiperovskites $(\mathbf{M}=\mathbf{L i}, \mathbf{N a})$. a Normalized (cubic) lattice parameters of $\mathrm{M}_{3} \mathrm{HCh}$. For orthorhombic o-Na $\mathrm{HS}$, the cubic lattice parameter is an average of normalized lattice parameters. Lines are for the eye guidance. $\mathbf{b}$ The hydride anion $\left(\mathrm{H}^{-}\right)$size obtained by subtracting $\mathrm{M}^{+}$radius from $\mathrm{H}^{-}-\mathrm{M}^{+}$bond length. Open triangles indicate the ionic radius of $\mathrm{H}^{-}$in hypothetical cubic c- $\mathrm{Na}_{3} \mathrm{HS}$, which is calculated by using the average normalized cubic lattice parameter of the orthorhombic o- $\mathrm{Na}_{3} \mathrm{HS}$. c BVS values for $\mathrm{Ch}^{2-}$. Open triangles indicate the $\mathrm{S}^{2-} \mathrm{BVS}$ for hypothetical cubic c$\mathrm{Na}_{3} \mathrm{HS}$. d Variation in bond length of $\mathrm{B}-\mathrm{M}$ in $\mathrm{BM}_{6}\left(\mathrm{~B}=\mathrm{H}^{-}, \mathrm{N}^{3-}, \mathrm{O}^{2-}, \mathrm{F}^{-}\right)$octahedra for $\mathrm{M}_{3} \mathrm{BA}$ antiperovskites and $\mathrm{B}-\mathrm{O}$ in $\mathrm{BO}_{6}\left(\mathrm{~B}=\mathrm{Fe}^{3+}, \mathrm{Cr}^{3+}, \mathrm{Zr}^{4+}\right)$ octahedra for $\mathrm{ABO}_{3}$ perovskites. The mentioned studies refer to Supplementary References (S1-S8).

quite anomalous. The $t$ value of the orthorhombic $\mathrm{Na}_{3} \mathrm{HS}$ is 0.84 , slightly smaller than that of cubic $\mathrm{Li}_{3} \mathrm{HS}(t=0.85)$.

Phase stability. Earlier studies on oxyhydrides have shown that the hydride anion $\left(\mathrm{H}^{-}\right)$adapts itself to the different local environments, resulting in the hydride size flexibility; this unique feature brings about a number of novel properties such as highpressure-induced coordination reversal in $\mathrm{LaHO}^{33,39-42}$. This means that our assumption of the fixed hydride size $(1.40 \AA)$ for calculating the tolerance factor was not adequate. Hence, we estimated the ionic radius of hydride anions, $\mathrm{r}\left(\mathrm{H}^{-}\right)$by subtracting the ionic radii of alkali metals, $\mathrm{r}\left(\mathrm{M}^{+}\right)$from the $\mathrm{H}-\mathrm{M}$ bond lengths ( $\mathrm{a} / 2$ in the case of the cubic system). Figure $3 \mathrm{~b}$ shows that the hydride substantially changes its size, with $\mathrm{r}\left(\mathrm{H}^{-}\right)$ranging from $1.17 \AA$ to $1.36 \AA$. For the $\mathrm{Li}_{3} \mathrm{HCh}$ series, $\mathrm{r}\left(\mathrm{H}^{-}\right)$expands nearly linearly with the $\mathrm{Ch}-\mathrm{M}$ bond length down the chalcogen group, in line with the increasing volume of $\mathrm{HLi}_{6}$ octahedron and $\mathrm{ChLi}_{12}$ cuboctahedron (Supplementary Fig. 10). A similar linear dependence can be recognized as long as the cubic phase of $\mathrm{Na}_{3} \mathrm{HCh}$ (including the hypothetical cubic $\mathrm{c}-\mathrm{Na}_{3} \mathrm{HS}$ ) is considered. Interestingly, the hydride size in the real orthorhombic o- $\mathrm{Na}_{3} \mathrm{HS}$ deviates from this linear relationship; $r\left(\mathrm{H}^{-}\right)$in $\mathrm{o}-\mathrm{Na}_{3} \mathrm{HS}$ greatly increases to the value closer to cubic $\mathrm{Na}_{3} \mathrm{HTe}$. The particularly soft anion $\left(\mathrm{H}^{-}\right)$with the flexible size is counterintuitive to the traditional hard-sphere model with fixed ionic radii when describing the bonding nature of ionic compounds.

To better understand the swollen $\mathrm{H}^{-}$in orthorhombic o$\mathrm{Na}_{3} \mathrm{HS}$, we calculated bond valence sum (BVS) values of chalcogenide using the tabulated parameters ${ }^{43}$. Note that the size flexibility of hydride anion does not permit a reliable estimate of BVS for the hydride anion itself ${ }^{40}$. As shown in Fig. 3c, the BVS value for $\mathrm{S}^{2-}$ in hypothetical $\mathrm{c}-\mathrm{Na}_{3} \mathrm{HS}$ is -1.16 , which is unusually low, indicating that $\mathrm{S}^{2-}$ is greatly underbonded in the cuboctahedral site. Here, the flexible hydride comes into play. In o- $\mathrm{Na}_{3} \mathrm{HS}$, the $\mathrm{HNa}_{6}$ octahedron (due to swollen $\mathrm{H}^{-}$) is greatly expanded (as displayed in Supplementary Fig. 10), which in turn reduces the $\mathrm{SNa}_{12}$ volume and allows $\mathrm{S}^{2-}$ to gain an acceptable BVS value of -1.60 . For the $\mathrm{Li}_{3} \mathrm{HCh}$ series, $\mathrm{Li}_{3} \mathrm{HS}$ has the lowest Ch-BVS value of -1.44 , which is higher than that for $\mathrm{Na}_{3} \mathrm{HSe}$ (-1.32).

Since we have estimated $\mathrm{r}\left(\mathrm{H}^{-}\right)$for each compound (Fig. 3b), we can redefine the tolerance factor $\left(t^{\prime}\right)$ (see Supplementary Table 6). It is found that cubic hydride antiperovskites have large $t^{\prime}$ from 0.93 to 0.99 , while orthorhombic $\mathrm{Na}_{3} \mathrm{HS}$ has $t^{\prime}=0.85$. The redefined $t^{\prime}$ for $\mathrm{Li}_{3} \mathrm{HCh}$ is closer to unity and has a narrower range. For example, $\mathrm{Li}_{3} \mathrm{HS}$ with a minimum $t$ of 0.85 changes to $t^{\prime}=0.95$ when the observed $\mathrm{r}\left(\mathrm{H}^{-}\right)$is applied. Therein lies the 
extraordinary size flexibility of hydride, that is, the marked variation in bond length of $\mathrm{H}-\mathrm{Li}$ in $\mathrm{HLi}_{6}$ octahedra, from a maximum of $2.11 \AA$ for $\mathrm{Li}_{3} \mathrm{HTe}$ to a minimum of $1.93 \AA$ for $\mathrm{Li}_{3} \mathrm{HS}$, as shown in Fig. 3d. The obtained bond-length difference of $0.09 \AA$ for hydride antiperovskites is much larger than those of other antiperovskites with $\mathrm{B}=\mathrm{N}(0.04 \AA), \mathrm{O}(0.03 \AA)$, and $\mathrm{F}$ $(0.01 \AA)$. However, from a broader perspective, antiperovskites generally have larger octahedral size variations than conventional oxide perovskites, developing the potential to tailor structures toward acquiring new functions.

Until now, we had a sharp picture of the large size variation of hydride anion. The chalcogenide anion, however, is also polarizable. To critically evaluate the role of anions in stabilizing the cubic structure, we estimated the radius of each ion using Bader population analysis, which partitions the first-principlescalculated charge density grid into the Bader region of each ion (see Methods in Supplementary Information) ${ }^{44}$. The resulting Bader radius of $\mathrm{Li}^{+}$only increases from 0.94 to $0.97 \AA$ when the A-site chalcogenide anion increase from $\mathrm{S}^{2-}$ to $\mathrm{Te}^{2-}$, whereas the Bader radius of $\mathrm{H}^{-}$ion expands from 1.38 to $1.48 \AA$ (Supplementary Table 7). The large size variation of $\mathrm{H}^{-}$is also evidenced in $\mathrm{Na}_{3} \mathrm{HCh}$. Interestingly, the change in Bader radius of $\mathrm{Ch}^{2-}$ ions is comparable to that of $\mathrm{H}^{-}$ions; the Bader radii of $\mathrm{Se}^{2-}$ and $\mathrm{H}^{-}$ are 2.06 and $1.42 \AA$, respectively, in $\mathrm{Li}_{3} \mathrm{HSe}$ and increase to 2.24 and $1.52 \AA$ in $\mathrm{Na}_{3} \mathrm{HSe}$. However, when applying the external pressure $(5 \mathrm{GPa})$ to $\mathrm{M}_{3} \mathrm{HCh}$, the Bader radius of $\mathrm{H}^{-}$decreases more substantially than that of $\mathrm{Ch}^{2-}$ (Supplementary Fig. 11). The hydride ion is more sensitive to the applied pressure than chalcogenide. Given that most of $\mathrm{M}_{3} \mathrm{HCh}$ compounds are currently synthesized by high pressure, we argue that the flexible hydride is more critical for stabilizing the cubic symmetry.

To investigate the thermodynamic stability of this series of hydride antiperovskites, we evaluated the formation enthalpy $\Delta H$ of $\mathrm{M}_{3} \mathrm{HCh}(\mathrm{M}=\mathrm{Li}, \mathrm{Na})$ in the reaction $\left(\mathrm{MH}+\mathrm{M}_{2} \mathrm{Ch} \rightarrow\right.$ $\mathrm{M}_{3} \mathrm{HCh}$ ) under 0 and $5 \mathrm{GPa}$ based on first-principles calculations, where $\Delta H$ is defined as $\Delta H=H\left(\mathrm{M}_{3} \mathrm{HCh}\right)-\left\{H\left(\mathrm{M}_{2} \mathrm{Ch}\right)+H\right.$ $(\mathrm{MH})$. Calculations showed that $\mathrm{Li}_{3} \mathrm{HS}, \mathrm{Na}_{3} \mathrm{HS}$, and $\mathrm{Na}_{3} \mathrm{HSe}$ are thermodynamically unstable at $0 \mathrm{GPa}(\Delta H>0)$, but are stabilized under high pressure (Fig. 4a). On the other hand, $\mathrm{Li}_{3} \mathrm{HTe}$ and $\mathrm{Na}_{3} \mathrm{HTe}$ with large $t$ ' values ( 0.99 and 0.96 , respectively) are stable even at ambient pressure. Hence, the proof-of-concept trial to synthesize $\mathrm{Na}_{3} \mathrm{HTe}$ was conducted by heating a mixed pellet of $\mathrm{NaH}$ and $\mathrm{Na}_{2} \mathrm{Te}$ at $400{ }^{\circ} \mathrm{C}$ overnight in a vacuum-sealed Pyrex tube. The resulting SXRD pattern (Supplementary Fig. 12) yielded a cubic phase with $a=4.76717(5) \AA$, which is identical with the sample obtained under high pressure $(a=4.76349(2) \AA)$ and antisite anion disorder exists in neither case (Supplementary Table 8). In addition, the Gibbs free energy difference $(\Delta G)$ showed that $\mathrm{Li}_{3} \mathrm{HSe}$ is stable at ambient pressure $(\Delta G=-0.01$ eV/f.u.), despite the slightly positive value of $\Delta H$ (Fig. 4a); our preliminary synthesis under simple ambient conditions has failed, but there remains room for adjusting parameters, such as partial $\mathrm{H}_{2}$ gas pressure.

Electron and phonon calculations. The electronic band structures at $0 \mathrm{GPa}$ (Supplementary Fig. 13) obtained using firstprinciples calculations show that all the compounds have relatively large bandgaps: $4.2 \mathrm{eV}$ for $\mathrm{Li}_{3} \mathrm{HS}, 3.5 \mathrm{eV}$ for $\mathrm{Li}_{3} \mathrm{HSe}, 2.9 \mathrm{eV}$ for $\mathrm{Li}_{3} \mathrm{HTe}, 2.9 \mathrm{eV}$ for $\mathrm{Na}_{3} \mathrm{HS}, 2.8 \mathrm{eV}$ for $\mathrm{Na}_{3} \mathrm{HSe}$ and $2.7 \mathrm{eV}$ for $\mathrm{Na}_{3} \mathrm{HTe}$. Although GGA-PBE exchange-correlation functional generally underestimates bandgaps ${ }^{45}$, our compounds are expected to have electronically good insulating properties to meet the requirements as a solid electrolyte.

Phonon band structures of the hydride antiperovskites at 0 and $5 \mathrm{GPa}$ were calculated using lattice dynamics within harmonic approximation (see Fig. $4 \mathrm{~b}, \mathrm{c}$ for $\mathrm{Li}_{3} \mathrm{HS}$ and Supplementary Fig. 14 for the others), including the hypothetical cubic $c-\mathrm{Na}_{3} \mathrm{HS}$. All the synthesized cubic compounds are found to be dynamically stable at $5 \mathrm{GPa}$. In contrast, the $\mathrm{c}-\mathrm{Na}_{3} \mathrm{HS}$ under 0 and $5 \mathrm{GPa}$ exhibits imaginary phonon modes at the $M$ and $R$ points, corresponding to in-phase and out-of-phase rotations of the $\mathrm{HM}_{6}$ octahedral rotation, respectively ${ }^{46}$, which as a result confirms the experimentally observed orthorhombic structure $\mathrm{o}-\mathrm{Na}_{3} \mathrm{HS}$ with the $a^{+} b^{-} b^{-}$tilting in Glazer notation. $\mathrm{Li}_{3} \mathrm{HSe}, \mathrm{Li}_{3} \mathrm{HTe}$, and $\mathrm{Na}_{3} \mathrm{HTe}$ are dynamically stable even at $0 \mathrm{GPa}$ without any imaginary phonon frequencies. For $\mathrm{Li}_{3} \mathrm{HS}$ and $\mathrm{Na}_{3} \mathrm{HSe}$ (dynamically stable at $5 \mathrm{GPa}$ ), imaginary phonon modes (lattice instabilities) appear at $\mathrm{M}$ and $\mathrm{R}$ points under $0 \mathrm{GPa}$, which is inconsistent with experimental observations of the cubic phase after quenching from $5 \mathrm{GPa}$; this inconsistency might be resolved by including anharmonic effects of phonons at finite temperatures, which is the case of cubic $\mathrm{SrTiO}_{3}{ }^{47}$.

The calculated phonon dispersions of $\mathrm{M}_{3} \mathrm{HCh}(\mathrm{M}=\mathrm{Li}, \mathrm{Na})$ and atom-projected phonon DOS are quite unique; high frequencies associated with optical phonons are ascribed to local vibrations of the lighter $\mathrm{H}^{-}$ion, whereas vibrations by heavier $\mathrm{M}^{+}$ and $\mathrm{Ch}^{2-}$ ions are responsible for low phonon frequencies, along with relatively flat dispersions. Furthermore, the phonon band center of $\mathrm{M}^{+}$ions decreases as the $\mathrm{Ch}^{2-}$ ion becomes larger (e.g., 9.6 to 9.2 to $8.4 \mathrm{THz}$ for $\mathrm{Li}_{3} \mathrm{HCh}$ ), suggesting a tunability of lattice softness for mobile $\mathrm{M}^{+}$ions. Given the concept of "the softer the lattice, the better"18,20,21,23,25,31 and the relatively large calculated bandgap, $\mathrm{M}_{3} \mathrm{HCh}$ antiperovskites should be a promising candidate as $\mathrm{Li} / \mathrm{Na}$ solid-state electrolytes. In the next section, we will explore ionic transport properties in this series of hydridebased antiperovskites from a theoretical and experimental point of view.

Ionic conductivity. Nudged elastic band (NEB) calculations were used to estimate the energy barrier for cationic transport. Previous studies on $\mathrm{Li}_{3} \mathrm{OCl}$ proposed two transport mechanisms, i.e., $\mathrm{Li}$ hopping via vacancy mechanism and $\mathrm{Li}$ interstitial dumbbell hopping along edges of $\mathrm{LiO}_{6}$ octahedra ${ }^{10,12}$. We calculated migration barriers for $\mathrm{Li} / \mathrm{Na}$ transport in $\mathrm{M}_{3} \mathrm{HCh}$ based on these two mechanisms, and the results are displayed in Fig. 5a for the vacancy mechanism and Fig. $5 b$ for the dumbbell mechanism. The energy barriers via vacancy mechanism range from $0.15 \mathrm{eV}$ (o- $\mathrm{Na}_{3} \mathrm{HS}$, Supplementary Fig. 15) to $0.32 \mathrm{eV}\left(\mathrm{Li}_{3} \mathrm{HTe}\right)$, while the dumbbell mechanism has a much smaller energy barrier from $0.05 \mathrm{eV}\left(\mathrm{Na}_{3} \mathrm{HSe}\right)$ to $0.14 \mathrm{eV}\left(\mathrm{Li}_{3} \mathrm{HTe}\right)$. The calculated energy barriers via both of mechanisms for $\mathrm{M}_{3} \mathrm{HCh}$ are notably low, and the difference of more than half between two mechanisms is also observed in previously reported antiperovskites (e.g., in $\mathrm{Li}_{3} \mathrm{OCl}$, $0.31 \mathrm{eV}$ and $0.15 \mathrm{eV}$ for vacancy and dumbbell mechanisms, respectively $)^{12}$. It should also be noted that the calculated migration barrier $(3.49 \mathrm{eV})$ for hydride $\left(\mathrm{H}^{-}\right)$hopping via vacancy in $\mathrm{Li}_{3} \mathrm{HS}$ (Supplementary Fig. 16) is much higher than that of $\mathrm{Li}^{+}$ $(0.20 \mathrm{eV})$, indicating that $\mathrm{H}^{-}$anions hardly migrate in our antiperovskite. From the results of potentiostatic measurement of the symmetric cell $\mathrm{Li}_{3} \mathrm{PS}_{4} / \mathrm{Li}_{2.9} \mathrm{H}\left(\mathrm{S}_{0.9} \mathrm{I}_{0.1}\right) / \mathrm{Li}_{3} \mathrm{PS}_{4}$, the steady-state current suggesting the sole motion of $\mathrm{Li}^{+}$in iodine-doped $\mathrm{Li}_{3} \mathrm{HS}$ is observed in Supplementary Fig. 17.

To our surprise, the energy barrier is largest for $\mathrm{Ch}=\mathrm{Te}$, followed by Se and S. This seems counterintuitive since the cell volume increases (corresponding to the widening of the channels for $\mathrm{Li} / \mathrm{Na}$ transport) as the ionic radius of chalcogenide ion increase from $\mathrm{S}$ to $\mathrm{Se}$ and then Te. At the same time, the phonon band center of $\mathrm{Li} / \mathrm{Na}$ becomes lower (enhancing the softness of lattice), which implies that other factors such as local lattice dynamics are playing a role in ion diffusion. A systematic 


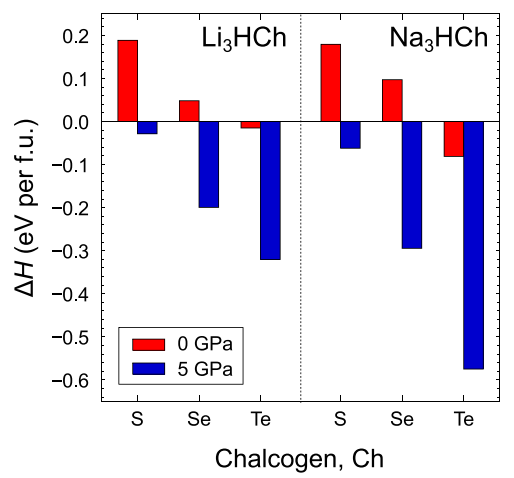

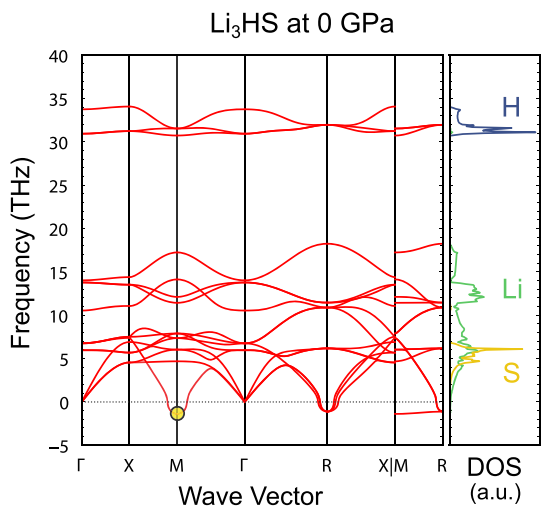

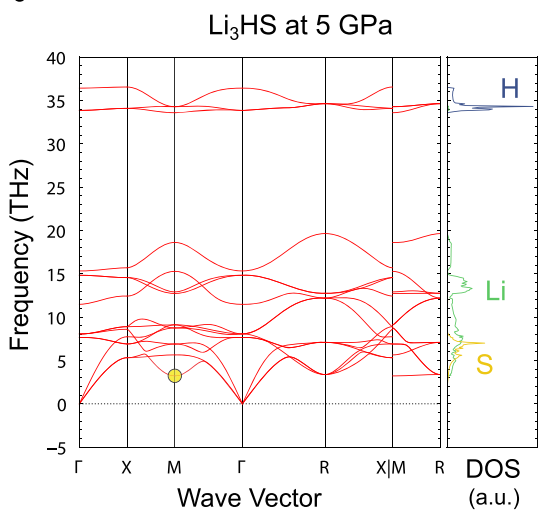

d

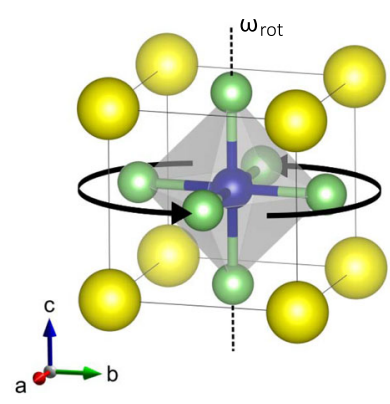

e

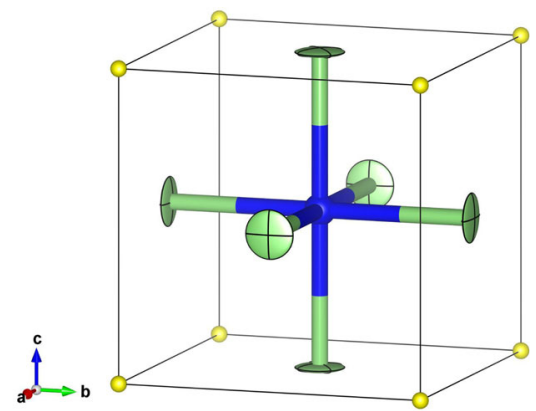

Fig. 4 Formation enthalpy and phonon calculations. a Formation enthalpy $\Delta H$ in the reaction $M H+M_{2} C h \rightarrow M M_{3} H C h(M=L i, N a)$ under 0 and $5 \mathrm{GPa}$. b Phonon band structures and partial phonon density of states (DOS) of $\mathrm{Li}, \mathrm{H}$, and $\mathrm{S}$ atoms in $\mathrm{Li}_{3} \mathrm{HS}$ under $\mathrm{O} \mathrm{GPa}$ and $\mathbf{c} 5 \mathrm{GPa}$. The negative number of the vertical axis represents imaginary frequency. $\mathbf{d ~ H M}$ octahedral rotation associated with the phonon mode denoted by yellow circles in phonon band dispersion, where $\omega_{\text {rot }}$ is the frequency of the $\mathrm{HM}_{6}$ rotational mode at $\mathrm{M}$ point. e Displacement ellipsoids of Li atoms depicted at $50 \%$ probability level obtained from Rietveld refinement of ND in $\mathrm{Li}_{3} \mathrm{HS}$.

investigation of phonon dispersions in $\mathrm{M}_{3} \mathrm{HCh}$ revealed that the rotational motion of the $\mathrm{HM}_{6}$ octahedron reflecting on the phonon mode at $\mathrm{M}$ point (Fig. $4 \mathrm{~d}$ ) is essential to understand the unusual Ch dependence. This rotational motion corresponds well to the migration direction of $\mathrm{M}^{+}$ions to adjacent sites and displacement ellipsoids (anisotropic atomic displacement parameters) of Li/Na (Fig. 4e) obtained from the Rietveld refinement conform well to the rotational mode. The frequency of this phonon mode, $\omega_{\text {rot }}$, decreases with decreasing the $\mathrm{Ch}^{2-}$ size $(1.4 i$, 3.7 and 5.7 THz for $\mathrm{Li}_{3} \mathrm{HS}, \mathrm{Li}_{3} \mathrm{HSe}$ and $\mathrm{Li}_{3} \mathrm{HTe}$ and $0.6 i$ and 2.1 $\mathrm{THz}$ for $\mathrm{Na}_{3} \mathrm{HSe}$ and $\mathrm{Na}_{3} \mathrm{HTe}$ ), demonstrating the softening of this specific rotational phonon. For both $\mathrm{Li} / \mathrm{Na}$ migration mechanism, $\omega_{\text {rot }}^{2} \cdot m_{\mathrm{M}}$ (where $m_{\mathrm{M}}$ is the atomic mass of $\mathrm{M}$ ), which corresponds to the force constant $k_{\text {rot }}$ with respect to the rotational motion, exhibits a positive linear correlation with energy barriers (Fig. 5c). The decreasing trend of $\omega_{\text {rot }}$ for $\mathrm{Te} \rightarrow \mathrm{Se}$ $\rightarrow \mathrm{S}$ is directly related to the dynamic stability or the phase transition between the cubic phase and the tilted orthorhombic phase (Fig. 4 and Supplementary Fig. 14). Thus, the softening of $\mathrm{M}^{+}$ion migration (or octahedral rotational) mode could be the origin of the low energy migration energy of hydride antiperovskites.

Experimentally, we measured lithium/sodium-ion conductivity of cold-pressed $\mathrm{M}_{3} \mathrm{HCh}$ samples $(\mathrm{M}=\mathrm{Li}, \mathrm{Na} ; \mathrm{Ch}=\mathrm{S}, \mathrm{Se}, \mathrm{Te})$ using electrochemical impedance spectroscopy (EIS). As a representative example, we show in Supplementary Fig. 18 Nyquist plots of $\mathrm{Na}_{3} \mathrm{HSe}$, featuring typical ionic impedance response with a semicircle which has a capacitance of $\sim 10^{-10} \mathrm{~F}$ at high frequencies and a low-frequency tail. Since the bulk and grain boundary resistance cannot be specifically deconvoluted ${ }^{48}$, the total conductivity in Fig. $5 \mathrm{~d}$ is attributed to the bulk and grain boundary resistance, which might be the reason why no clear trend in the composition dependence of ionic conductivity is observed. The activation energies obtained from the Arrhenius fit for the pristine $\mathrm{M}_{3} \mathrm{HCh}$ (Fig. $5 \mathrm{~d}$ ) are in the range of 0.44 to 0.53 $\mathrm{eV}$ for cubic phases and $0.30 \mathrm{eV}$ for orthorhombic $\mathrm{Na}_{3} \mathrm{HS}$, which are comparable with other superionic conductors such as garnet $\mathrm{Li}_{7} \mathrm{La}_{3} \mathrm{Nb}_{2} \mathrm{O}_{12}{ }^{49}$ and $\beta-\mathrm{Li}_{3} \mathrm{PS}_{4}{ }^{50}$. Compared with the computed migration barrier (Fig. 5a, b), the experimentally obtained activation energy (Fig. 5d) is relatively large. The discrepancy might result from two facts: the low concentration of intrinsic charge carriers (i.e., vacancies/interstitials) which we expect in the synthesized sample, whereas the calculated migration barriers assume intrinsic vacancies or interstitials of lithium/sodium. In addition, the migration barrier is separate from defect formation energy (which we list in Supplementary Table 9), whereas they are reflected in the experimental activation energies. Moreover, the computed compositional dependence (Fig. 5c) is not observed, probably due to the non-negligible resistive grain boundary and interfacial impacts on the conductivity measurement ${ }^{51}$.

Here, we take the cubic $\mathrm{Na}_{3} \mathrm{HSe}$ compound as an example to fulfill the potential of the deformable anion matrix for fast sodium ionic diffusion. When creating a small number of sodium vacancies in $\mathrm{Na}_{2.9} \mathrm{H}\left(\mathrm{Se}_{0.9} \mathrm{I}_{0.1}\right)$, the total ionic conductivity increased to $\sim 1 \times 10^{-4} \mathrm{~S} / \mathrm{cm}$ at $100^{\circ} \mathrm{C}$ with two orders of magnitude higher than the undoped one (Fig. 6a). It is also noteworthy that the Nyquist plots of I-doped $\mathrm{Na}_{2.9} \mathrm{H}\left(\mathrm{Se}_{0.9} \mathrm{I}_{0.1}\right)$ sample at a lower temperature (Supplementary Fig. 19) show two semicircles at the high frequency where the small half-semicircle 
a

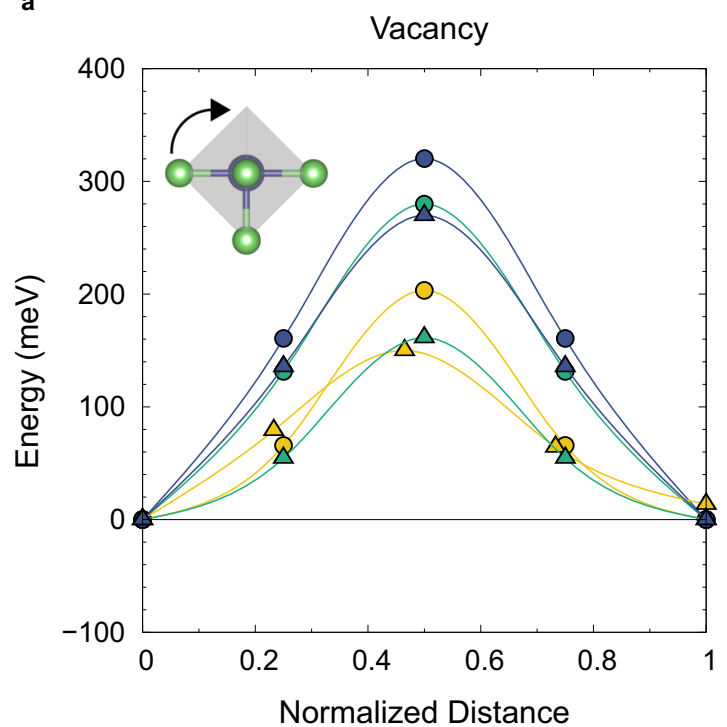

C

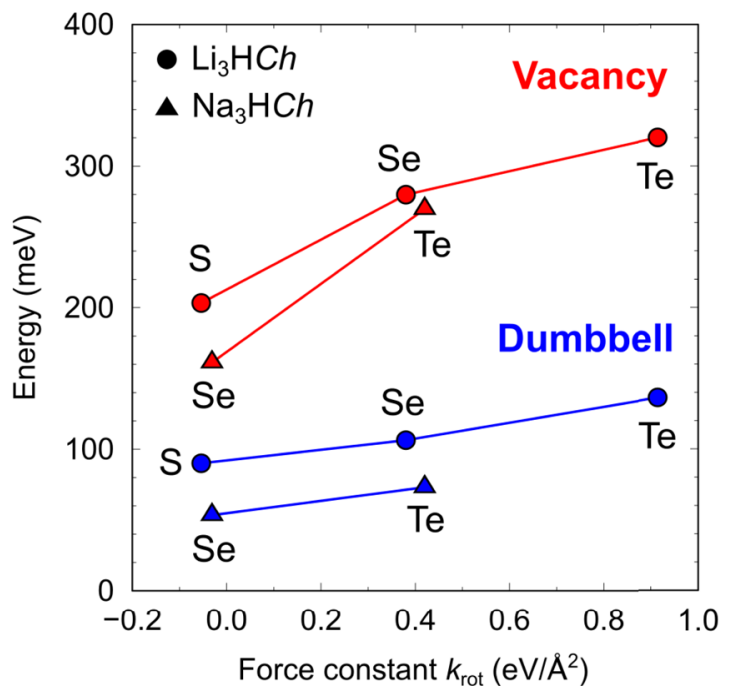

b

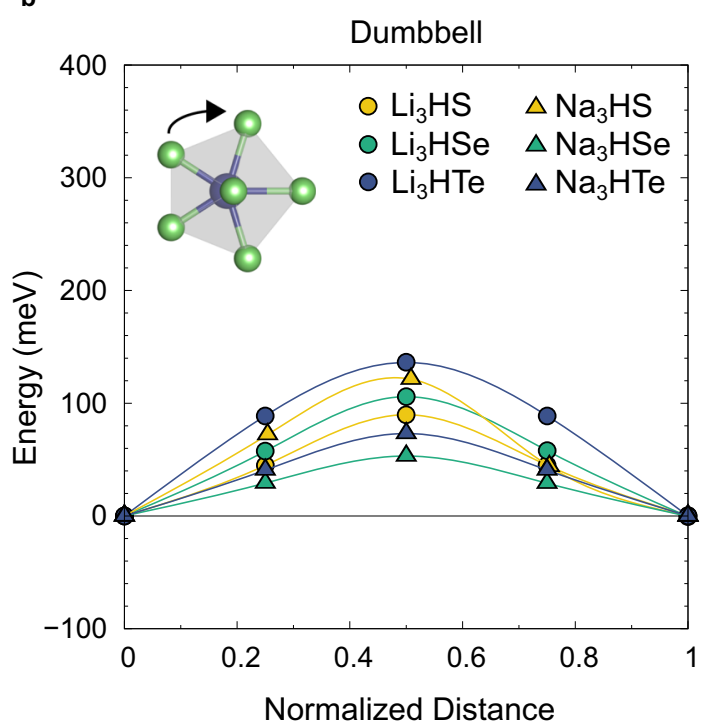

d

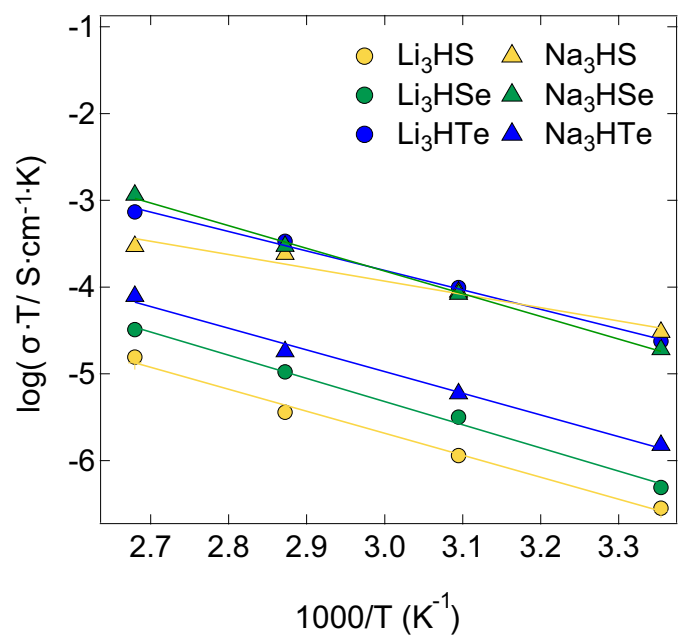

Fig. $\mathbf{5}$ lonic conductivities of $\mathbf{M}_{\mathbf{3}} \mathbf{H C h}$ antiperovskites $(\mathbf{M}=\mathbf{L i}, \mathbf{N a}$, and $\mathbf{C h}=\mathbf{S}, \mathbf{S e}, \mathbf{T e})$. Low-barrier migration pathways for a vacancy and $\mathbf{b}$ interstitial dumbbell migration in $\mathrm{M}_{3} \mathrm{HCh}$. Top-left insets show $\mathrm{M}^{+}$migration when viewing $\mathrm{HM}_{6}$ octahedron from the top to down. For orthorhombic $\mathrm{Na}_{3} \mathrm{HS}$, there are many migration pathways, one of which is shown as a representative example (see Supplementary Fig. 15 for details). c Migration barriers for cation transport via the vacancy and interstitial dumbbell mechanism in $\mathrm{M}_{3} \mathrm{HCh}$ as a function of the force constant $k_{\text {rot }}$ with respect to the $\mathrm{HM}_{6}$ rotational motion. d Arrhenius plots of the total conductivity values for undoped $\mathrm{M}_{3} \mathrm{HCh}$ cold-pressed samples in the temperature range from 25 to $100{ }^{\circ} \mathrm{C}$.

corresponds to the grain/bulk resistance and a low-frequency tail. As shown in Fig. 6b, the bulk activation energy for sodium-ion transport in $\mathrm{Na}_{2.9} \mathrm{H}\left(\mathrm{Se}_{0.9} \mathrm{I}_{0.1}\right)$ is determined as $E_{\mathrm{a} \text {,bulk }}=0.18 \mathrm{eV}$, which is close to the calculated migration barrier of $0.16 \mathrm{eV}$ via vacancy mechanism in $\mathrm{Na}_{3} \mathrm{HSe}$ (Fig. 5a). Detailed structural characterization of $\mathrm{Na}_{2.9} \mathrm{H}\left(\mathrm{Se}_{0.9} \mathrm{I}_{0.1}\right)$ is shown in Supplementary Fig. 20 and Supplementary Table 10.

The ${ }^{23} \mathrm{Na}$ NMR data (Fig. 6c) exhibit a distinct behavior associated with the bulk diffusion of $\mathrm{Na}^{+}$ions in pristine and Idoped samples. The analysis of the spectra revealed that quadrupole interaction is dominant in $\mathrm{Na}_{2.9} \mathrm{H}\left(\mathrm{Se}_{0.9} \mathrm{I}_{0.1}\right)$ reflecting the faster $\mathrm{Na}^{+}$diffusion, whereas dipole-dipole interactions of the ${ }^{23} \mathrm{Na}$ nuclei are non-averaged in the isostructural $\mathrm{Na}_{3} \mathrm{HSe}$, $\mathrm{Na}_{3} \mathrm{HTe}$, and I-doped variant ${ }^{52}$. The line width of iodine-doped sample is narrower than that of undoped one, implying that faster short-range (i.e., bulk) ion dynamics. Furthermore, the line widths of $\mathrm{Na}_{3} \mathrm{HTe}$ NMR spectra (Supplementary Fig. 21) were observed to decrease with increasing temperature (known as motional narrowing) and dipole-dipole interactions are progressively averaged due to the thermally activated motion of the $\mathrm{Na}$ ions ${ }^{21}$. The enhancement of $\mathrm{Na}^{+}$conductivity we have achieved by the common aliovalent substitution approach promises the excellent potential of soft hydride-chalcogenide anion framework for $\mathrm{Li}^{+} / \mathrm{Na}^{+}$diffusion. There is still much room for improvement, such as mixed halide doping in A and/or B site, in future owing to the versatility of the perovskite-based crystal structures.

\section{Discussion}

By exploiting the simple but unique hydride anion, a series of antiperovskites with the formula of $\mathrm{M}_{3} \mathrm{HCh}(\mathrm{M}=\mathrm{Li}, \mathrm{Na} ; \mathrm{Ch}=\mathrm{S}$, $\mathrm{Se}, \mathrm{Te}$ ) has been successfully synthesized. Detailed structural characterizations demonstrate that the highly flexible size of hydride in the octahedral center explains the robustness of the ideal cubic structure in a wide compositional range with a $0.09 \AA$ $\mathrm{H}-\mathrm{M}$ bond difference, much longer than other antiperovskites 


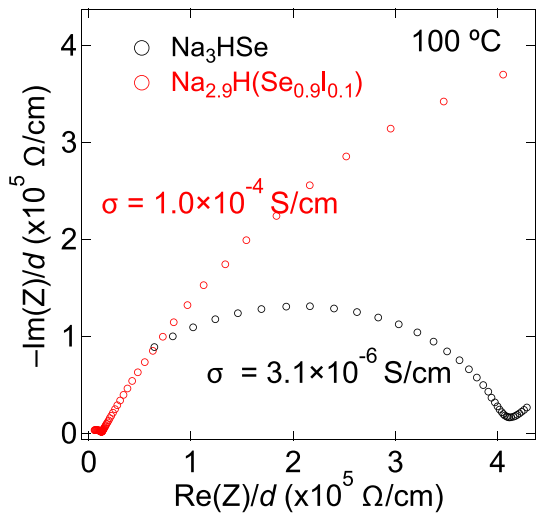

b

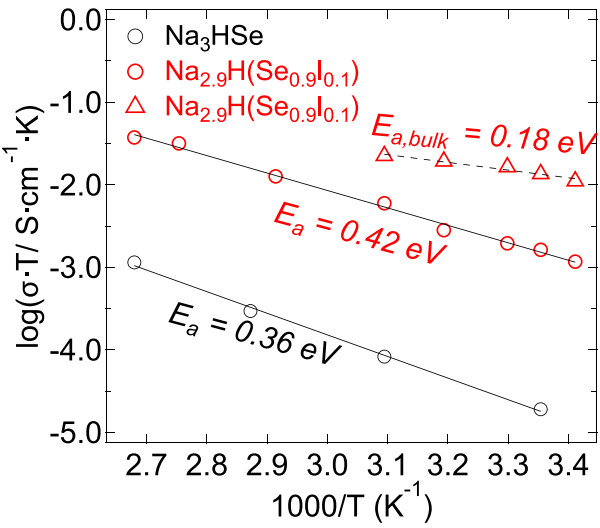

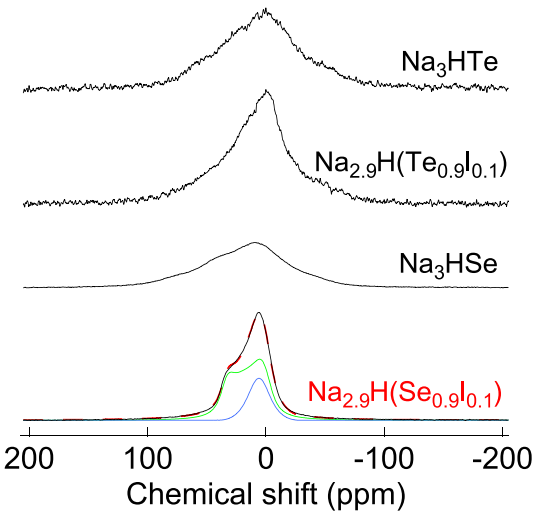

Fig. $6 \mathbf{~ N a}{ }^{+}$diffusion in $\mathbf{N a}_{\mathbf{3}} \mathbf{H S e}$ and $\mathbf{N a}_{\mathbf{2 . 9}} \mathbf{H}\left(\mathbf{S e}_{\mathbf{0 . 9}} \mathbf{I}_{\mathbf{0 . 1}}\right)$. a Impedance plots at $100^{\circ} \mathrm{C}$ of the cold-pressed pellets and the impedance is normalized to the respective pellet thickness. b Arrhenius plots of the total conductivity (circles) and bulk conductivity (triangles). c ${ }^{23} \mathrm{Na}$ static $\mathrm{NMR}$ spectra measured under $7 \mathrm{~T}$ at room temperature. For $\mathrm{Na}_{2.9} \mathrm{H}\left(\mathrm{Se}_{0.9} \mathrm{l}_{0.1}\right.$ ), observed spectra (black solid), fitting spectra (red dashed), and deconvolved peak 1 with $\mathrm{C}_{\mathrm{Q}}=1.30$ $\mathrm{MHz}, \eta=0.16$ (green) and peak 2 with $\mathrm{C}_{\mathrm{Q}}=1.33 \mathrm{MHz}, \eta=0.03$ (blue).

and perovskites. Theoretically, the family of LiRAPs and NaRAPs composed by soft anion sublattices of polarizable hydride and chalcogenide are shown to have low migration barriers for $\mathrm{Li} / \mathrm{Na}$ bulk transport, where the rotational phonon mode by $\mathrm{HM}_{6}$ octahedron possibly facilitates the Li/Na migration. Experimentally, high conductivity and low bulk activation energy have been demonstrated in the iodine-doped $\mathrm{Na}_{2.9} \mathrm{H}\left(\mathrm{Se}_{0.9} \mathrm{I}_{0.1}\right)$, with the total ionic conductivity of $1 \times 10^{-4} \mathrm{~S} / \mathrm{cm}$ at $100^{\circ} \mathrm{C}$. Further optimization through structural design and chemical doping would promise to achieve their full potential. The exploitation of size-flexible hydride anion developed in this work will be favorable for other ion-conducting materials, also help to induce novel states of matter and excitation phenomena.

\section{Methods}

Materials synthesis. Polycrystalline $\mathrm{M}_{3} \mathrm{HCh}$ samples $(\mathrm{M}=\mathrm{Li}, \mathrm{Na}$; $\mathrm{Ch}=\mathrm{S}, \mathrm{Se}, \mathrm{Te})$ were synthesized via high-pressure solid-state reactions using $\mathrm{MH}$ and $\mathrm{M}_{2} \mathrm{Ch}$ as starting reagents. We used as-received $\mathrm{LiH}$ (Sigma-Aldrich, 99\%), $\mathrm{Li}_{2} \mathrm{~S}$ (SigmaAldrich, 99\%), $\mathrm{NaH}$ (Sigma-Aldrich, 99\%), $\mathrm{Na}_{2} \mathrm{~S}$ (Sigma-Aldrich, 99\%), $\mathrm{Na}_{2} \mathrm{Se}$ (Kojundo, 99\%), $\mathrm{Na}_{2} \mathrm{Te}$ (Kojundo, $99 \%$ ), while $\mathrm{Li}_{2} \mathrm{Se}$ and $\mathrm{Li}_{2} \mathrm{Te}$ were prepared using $\mathrm{LiEt}_{3} \mathrm{BH}$ (Sigma-Aldrich), Se (Rare Metallic Co., LTD., 99.9\%) and Te (Rare Metallic Co., LTD., 99.9\%). There is a tendency that excess use of alkali metal hydride improves sample purity. The starting materials were well-ground and pelletized, and the pellets were inserted into a boron nitride (BN) sleeve. The two ends of the sleeve were then sealed with $\mathrm{BN}$ caps. The assemble was loaded into a graphite tube heater and then enclosed in a pyrophyllite cube serving as a pressure medium. All above procedures were handled in a $\mathrm{N}_{2}$-filled glovebox due to air and moisture sensitivity of the precursors and synthesized materials. Finally, the assembly was pressed at $5 \mathrm{GPa}$, heated to $700^{\circ} \mathrm{C}$ in $10 \mathrm{~min}$, kept for $2 \mathrm{~h}$, and cooled down to room temperature in $5 \mathrm{~min}$ before pressure was released. All the iodinedoped samples (e.g., $\mathrm{Na}_{2.9} \mathrm{H}\left(\mathrm{Se}_{0.9} \mathrm{I}_{0.1}\right), \mathrm{Na}_{2.9} \mathrm{H}\left(\mathrm{Te}_{0.9} \mathrm{I}_{0.1}\right), \mathrm{Li}_{2.9} \mathrm{H}\left(\mathrm{S}_{0.9} \mathrm{I}_{0.1}\right)$ ) were successfully synthesized using NaI/LiI (Sigma-Aldrich, 99\%) as iodine source under the same condition with undoped one.

Powder X-ray and neutron diffraction. We characterized the purity and crystal structures of as-prepared $\mathrm{M}_{3} \mathrm{HCh}$ samples at room temperature by powder X-ray diffraction (XRD) measurements using Rigaku Smart Lab with $\mathrm{Cu}$ radiation and Bruker D8 ADVANCE with Mo radiation. High-resolution synchrotron XRD experiments (SXRD) were performed at BL02B2 of SPring-8 (Japan) equipped with MYTHEN solid-state detectors. Time-of-flight(TOF) powder neutron diffraction (ND) data of $\mathrm{Li}_{3} \mathrm{HS}$ and $\mathrm{Na}_{3} \mathrm{HS}$ samples were collected on iMATERIA and SPICA diffractometers installed at the Material and Life science Facility (MLF) in the Japan Proton Accelerator Research Complex (J-PARC). The powder samples were sealed in cylindrical vanadium cells of dimensions $6 \mathrm{~mm}$ in diameter, $55 \mathrm{~mm}$ in height, and $100 \mu \mathrm{m}$ in thickness. Rietveld refinements were performed on neutron data taken at the backscattering bank $\left(2 \theta=155^{\circ}\right.$ for iMATERIA and $2 \theta=160.77^{\circ}$ for SPICA). Data were evaluated and refined using the FULLPROF suite, JANA2006, and Z-Rietveld softwares ${ }^{53}$. VESTA was used to display crystal structure and to calculate geometric properties.
Impedance spectroscopy. Ionic conductivities of cold-pressed pellets of $\mathrm{M}_{3} \mathrm{HCh}$ were measured by electrochemical impedance spectroscopy (EIS) with a constant voltage of $10 \mathrm{mV}$ in the frequency range of $1 \mathrm{MHz}$ to $0.1 \mathrm{~Hz}$ using an ECS Modulab potentiostat/galvanostat. Around $80 \mathrm{mg}$ of the specimen was placed between two stainless-steel rods as an ion-blocking electrode in a custom-made Swagelok cell and pressed into a $10 \mathrm{~mm}$ diameter pellet by a hydraulic press at $18 \mathrm{MPa}$ for $1 \mathrm{~min}$ in an Ar-filled glovebox. For activation energy measurements, we applied a temperature loop starting from $25^{\circ} \mathrm{C}$ to $100{ }^{\circ} \mathrm{C}$. The measurements at each temperature were collected after being held for $3 \mathrm{~h}$ to ensure the temperature stabilization. All equivalent circuits of Nquist plots were fitted using the EC-Lab software package Z-fit.

NMR spectroscopy. ${ }^{23} \mathrm{Na}$ NMR measurements were performed using JNMECA300 under $7 \mathrm{~T}$ with the ${ }^{23} \mathrm{Na}$ Lamor frequency of $79.5 \mathrm{MHz}$ and ECA600 (JEOL) under $14 \mathrm{~T}$ with $158.8 \mathrm{MHz}$ frequency. For magic-angle spinning (MAS) NMR, the sample was packed into a $4-\mathrm{mm}$ zirconia rotor in an Ar-filled glovebox and the spinning speed was $10 \mathrm{kHz}$. For variable-temperature ${ }^{23} \mathrm{Na}$ static NMR, the sample was sealed in an evacuated borosilicate glass tube. The ${ }^{23} \mathrm{Na}$ chemical shifts of all spectra were referenced to $1 \mathrm{M} \mathrm{NaCl}$ aqueous solution at 0 ppm and the peaks of the spectra were deconvoluted using a Dmfit program. To assign the observed ${ }^{23} \mathrm{Na}$ spectra, first-principles calculations based on DFT were carried out using the WIEN2k codes 54,55 . The muffin-tin radius, $R_{\mathrm{MT}}$, of $\mathrm{Na}, \mathrm{H}$, and Se atoms was 2.0,1.5, and 2.0, respectively, for cubic $\mathrm{Na}_{3} \mathrm{HSe}$. The volume optimization was performed prior to the chemical shift calculation. Self-

consistent cycles were carried out at an energy convergence of $0.0001 \mathrm{Ry}$. The $R_{\mathrm{MT}} K_{\max }$ determining the number of basis function was set to $7.0, G_{\max }$ was 12 , and the number of $k$-points in the irreducible Brillouin zone was 35 . The electric-field gradient (EFG), the asymmetry parameter $(y)$, and the magnetic shielding coefficient $\left(\sigma_{\text {iso }}\right)$ were calculated for the final optimized structure. To convert $\sigma_{\text {iso }}$ into the chemical shift $\left(\delta_{\text {iso }}\right)$ for comparison, $\sigma_{\text {iso }}$ of $\mathrm{Na}_{2} \mathrm{SiO}_{3}$ with $\delta_{\text {iso }}=20.0 \mathrm{ppm}{ }^{56}, \alpha-\mathrm{Na}_{2} \mathrm{Si}_{2} \mathrm{O}_{5}$ with $\delta_{\text {iso }}=17.4 \mathrm{ppm}^{52}$, and $\mathrm{Na}_{2} \mathrm{SO}_{4}$ with $\delta_{\text {iso }}=-8.5 \mathrm{ppm}^{52}$ were calculated in the same manner.

\section{Data availability}

The data that support the findings of this study are available from the corresponding author upon reasonable request.

Received: 24 April 2020; Accepted: 27 November 2020; Published online: 08 January 2021

\section{References}

1. Jeon, N. J. et al. Compositional engineering of perovskite materials for highperformance solar cells. Nature 517, 476-480 (2015).

2. Yang, W. S. et al. High-performance photovoltaic perovskite layers fabricated through intramolecular exchange. Science 348, 1234-1237 (2015).

3. Kamishima, K. et al. Giant magnetoresistance in the intermetallic compound $\mathrm{Mn}_{3}$ GaC. Phys. Rev. B 63, 024426 (2001).

4. He, T. et al. Superconductivity in the non-oxide perovskite $\mathrm{MgCNi}_{3}$. Nature 411, 54-56 (2001). 
5. Song, $\mathrm{X}$. et al. Adjustable zero thermal expansion in antiperovskite manganese nitride. Adv. Mater. 23, 4690-4694 (2011).

6. Takenaka, K. \& Takagi, H. Zero thermal expansion in a pure-form antiperovskite manganese nitride. Appl. Phys. Lett. 94, 131904 (2009).

7. Jia, X. et al. $\mathrm{Ni}_{3} \mathrm{FeN}$ nanoparticles derived from ultrathin $\mathrm{NiFe}$-layered double hydroxide nanosheets: an efficient overall water splitting electrocatalyst. $A d v$. Energy Mater. 6, 1502585 (2016).

8. Takahashi, T. \& Yamamoto, O. The $\mathrm{Ag} / \mathrm{Ag}_{3} \mathrm{SI} / \mathrm{I}_{2}$ solid-electrolyte cell. Electrochim. Acta 11, 779-789 (1966).

9. Lai, K. T., Antonyshyn, I., Prots, Y. \& Valldor, M. Anti-perovskite Li-battery cathode materials. J. Am. Chem. Soc. 139, 9645-9649 (2017).

10. Zhao, Y. \& Daemen, L. L. Superionic conductivity in lithium-rich antiperovskites. J. Am. Chem. Soc. 134, 15042-15047 (2012).

11. Lü, X. et al. Antiperovskite $\mathrm{Li}_{3} \mathrm{OCl}$ superionic conductor films for solid-state Li-ion batteries. Adv. Sci. 3, 1500359 (2016).

12. Emly, A., Kioupakis, E. \& Van Der Ven, A. Phase stability and transport mechanisms in antiperovskite $\mathrm{Li}_{3} \mathrm{OCl}$ and $\mathrm{Li}_{3} \mathrm{OBr}$ superionic conductors. Chem. Mater. 25, 4663-4670 (2013).

13. Sun, Y. et al. Rotational cluster anion enabling superionic conductivity in sodium-rich antiperovskite $\mathrm{Na}_{3} \mathrm{OBH}_{4}$. J. Am. Chem. Soc. 141, 5640-5644 (2019).

14. Andersen, N. H., Kjems, J. K. \& Hayes, W. Ionic conductivity of the perovskites $\mathrm{NaMgF}_{3}, \mathrm{KMgF}_{3}, \mathrm{KMgK}_{3}$ and $\mathrm{KZnF}_{3}$ at high temperatures. Solid State Ion. 17, 143-145 (1985).

15. Deng, Z., Radhakrishnan, B. \& Ong, S. P. Rational composition optimization of the lithium-rich $\mathrm{Li}_{3} \mathrm{OCl}_{1-\mathrm{x}} \mathrm{Br}_{\mathrm{x}}$ anti-perovskite superionic conductors. Chem. Mater. 27, 3749-3755 (2015).

16. Kim, K. \& Siegel, D. J. Correlating lattice distortions, ion migration barriers, and stability in solid electrolytes. J. Mater. Chem. A 7, 3216-3227 (2019).

17. Hanghofer, I. et al. Untangling the structure and dynamics of lithium-rich anti-perovskites envisaged as solid electrolytes for batteries. Chem. Mater. 30, 8134-8144 (2018).

18. Ohno, S. et al. Materials design of ionic conductors for solid state batteries. Prog. Energy 2, 022001 (2020).

19. Smith, J. G. \& Siegel, D. J. Low-temperature paddle-wheel effect in glassy solid electrolytes. Nat. Commun. 11, 1-11 (2020).

20. Jansen, M. Volume effect or paddle-wheel mechanism-fast alkali-metal ionic conduction in solids with rotationally disordered complex anions. Angew. Chem. Int. Ed. 30, 1547-1558 (1991).

21. Gao, Y. et al. Classical and emerging characterization techniques for investigation of ion transport mechanisms in crystalline fast ionic conductors. Chem. Rev. 120, 5954-6008 (2020).

22. Bachman, J. C. et al. Inorganic solid-state electrolytes for lithium batteries: mechanisms and properties governing ion conduction. Chem. Rev. 116, 140-162 (2016).

23. Kraft, M. A. et al. Influence of lattice polarizability on the ionic conductivity in the lithium superionic argyrodites $\mathrm{Li}_{6} \mathrm{PS}_{5} \mathrm{X}(\mathrm{X}=\mathrm{Cl}, \mathrm{Br}, \mathrm{I})$. J. Am. Chem. Soc. 139, 10909-10918 (2017).

24. He, X., Zhu, Y. \& Mo, Y. Origin of fast ion diffusion in super-ionic conductors. Nat. Commun. 8, 15893 (2017).

25. Krauskopf, T. et al. Comparing the descriptors for investigating the influence of lattice dynamics on ionic transport using the superionic conductor $\mathrm{Na}_{3} \mathrm{PS}_{4-\mathrm{x}} \mathrm{Se}_{\mathrm{x}}$. J. Am. Chem. Soc. 140, 14464-14473 (2018).

26. Muy, S. et al. Tuning mobility and stability of lithium ion conductors based on lattice dynamics. Energy Environ. Sci. 11, 850-859 (2018).

27. Wang, Y. et al. Design principles for solid-state lithium superionic conductors. Nat. Mater. 14, 1026-1031 (2015).

28. Di Stefano, D. et al. Superionic diffusion through frustrated energy landscape. Chem 5, 2450-2460 (2019).

29. Hanghofer, I., Gadermaier, B. \& Wilkening, H. M. R. Fast rotational dynamics in argyrodite-type $\mathrm{Li}_{6} \mathrm{PS}_{5} \mathrm{X}(\mathrm{X}: \mathrm{Cl}, \mathrm{Br}, \mathrm{I})$ as seen by ${ }^{31} \mathrm{P}$ nuclear magnetic relaxation on cation-anion coupled transport in thiophosphates. Chem. Mater. 31, 4591-4597 (2019).

30. Kweon, K. E. et al. Structural, chemical, and dynamical frustration: origins of superionic conductivity in closo-borate solid electrolytes. Chem. Mater. 29, 9142-9153 (2017).

31. Krauskopf, T., Pompe, C., Kraft, M. A. \& Zeier, W. G. Influence of lattice dynamics on $\mathrm{Na}^{+}$transport in the solid electrolyte $\mathrm{Na}_{3} \mathrm{PS}_{4-\mathrm{x}} \mathrm{Se}_{\mathrm{x}}$. Chem. Mater. 29, 8859-8869 (2017).

32. Kamaya, N. et al. A lithium superionic conductor. Nat. Mater. 10, 682-686 (2011).

33. Kageyama, H. et al. Expanding frontiers in materials chemistry and physics with multiple anions. Nat. Commun. 9, 772 (2018).

34. Mohtadi, R. \& Orimo, S. I. The renaissance of hydrides as energy materials. Nat. Rev. Mater. 2, 16091 (2016)

35. Kohlmann, H., Skripov, A. V., Soloninin, A. V. \& Udovic, T. J. The antiperovskite type hydride $\operatorname{InPd}_{3} \mathrm{H}_{0.89}$. J. Solid State Chem. 183, 2461-2465 (2010).
36. Shannon, R. D. Revised effective ionic radii and systematic studies of interatomic distances in halides and chalcogenides. Acta Crystallogr. Sect. A 32, 751-767 (1976)

37. Nuss, J., Mühle, C., Hayama, K., Abdolazimi, V. \& Takagi, H. Tilting structures in inverse perovskites, $\mathrm{M}_{3} \mathrm{TtO}(\mathrm{M}=\mathrm{Ca}, \mathrm{Sr}, \mathrm{Ba}, \mathrm{Eu} ; \mathrm{Tt}=\mathrm{Si}, \mathrm{Ge}, \mathrm{Sn}$, $\mathrm{Pb}$ ). Acta Crystallogr. B 71, 300-312 (2015).

38. Goldschmidt, V. M. Die Gesetze der Krystallochemie. Naturwissenschaften 14, 477-485 (1926).

39. Masuda, N. et al. Hydride in $\mathrm{BaTiO}_{2.5} \mathrm{H}_{0.5}$ : a labile ligand in solid state chemistry. J. Am. Chem. Soc. 137, 15315-15321 (2015).

40. Yamashita, H. et al. Chemical pressure-induced anion order-disorder transition in LnHO enabled by hydride size flexibility. J. Am. Chem. Soc. 140, 11170-11173 (2018)

41. Broux, T. et al. High-pressure polymorphs of LaHO with anion coordination reversal. J. Am. Chem. Soc. 141, 8717-8720 (2019).

42. Kobayashi, Y., Tsujimoto, Y. \& Kageyama, H. Property engineering in perovskites via modification of anion chemistry. Annu. Rev. Mater. Res. 48, 303-326 (2018).

43. Brese, N. E. \& O'Keeffe, M. Bond-valence parameters for solids. Acta Crystallogr. B 47, 192-197 (1991).

44. Tang, W., Sanville, E. \& Henkelman, G. A grid-based Bader analysis algorithm without lattice bias. J. Phys. Condens. Matter 21, 84204 (2009).

45. Hinuma, Y., Grüneis, A., Kresse, G. \& Oba, F. Band alignment of semiconductors from density-functional theory and many-body perturbation theory. Phys. Rev. B 90, 155405 (2014).

46. Cancellieri, C. et al. Polaronic metal state at the $\mathrm{LaAlO}_{3} / \mathrm{SrTiO}_{3}$ interface. Nat Commun. 7, 10386 (2016)

47. Tadano, T. \& Tsuneyuki, S. Self-consistent phonon calculations of lattice dynamical properties in cubic $\mathrm{SrTiO}_{3}$ with first-principles anharmonic force constants. Phys. Rev. B 92, 054301 (2015).

48. Irvine, J. T. S., Sinclair, D. C. \& West, A. R. Electroceramics: characterization by impedance spectroscopy. Adv. Mater. 2, 132-138 (1990).

49. Thangadurai, V., Kaack, H. \& Weppner, W. J. F. Novel fast lithium ion conduction in garnet-type $\mathrm{Li}_{5} \mathrm{La}_{3} \mathrm{M}_{2} \mathrm{O}_{12}(\mathrm{M}=\mathrm{Nb}$, Ta). J. Am. Ceram. Soc. 86, 437-440 (2003).

50. Liu, Z. et al. Anomalous high ionic conductivity of nanoporous $\beta-\mathrm{Li}_{3} \mathrm{PS}_{4}$. J. Am. Chem. Soc. 135, 975-978 (2013).

51. Dawson, J. A., Canepa, P., Famprikis, T., Masquelier, C. \& Islam, M. S. Atomic-scale influence of grain boundaries on Li-ion conduction in solid electrolytes for all-solid-state batteries. J. Am. Chem. Soc. 140, 362-368 (2018).

52. Koller, H., Engelhardt, G., Kentgens, A. P. M. \& Sauer, J. ${ }^{23}$ Na NMR spectroscopy of solids: interpretation of quadrupole interaction parameters and chemical shifts. J. Physial Chem. 98, 1544-1551 (1994).

53. Oishi, R. et al. Rietveld analysis software for J-PARC. Nucl. Instrum. Methods Phys. Res. Sect. A Accel. Spectrometers, Detect. Assoc. Equip. 600, 94-96 (2009).

54. Oikawa, I. \& Takamura, H. ${ }^{45} \mathrm{Sc}$ NMR spectroscopy and first-principles calculation on the symmetry of $\mathrm{ScO}_{6}$ polyhedra in $\mathrm{BaO}-\mathrm{Sc}_{2} \mathrm{O}_{3}$-based oxides. Dalt. Trans. 43, 9714-9721 (2014).

55. Blaha, P. et al. WIEN2k: an APW+lo program for calculating the properties of solids. J. Chem. Phys. 152, 074101 (2020).

56. Jones, A. R., Winter, R., Neville Greaves, G. \& Smith, I. H. ${ }^{23} \mathrm{Na},{ }^{29} \mathrm{Si}$, and ${ }^{13} \mathrm{C}$ MAS NMR investigation of glass-forming reactions between $\mathrm{Na}_{2} \mathrm{CO}_{3}$ and $\mathrm{SiO}_{2}$. J. Phys. Chem. B 109, 23154-23161 (2005).

\section{Acknowledgements}

This work was supported by Grants-in-Aid for Scientific Research on Innovative Areas "Mixed Anion" (No. JP16H06439; JP16H06440; JP16H06441; JP17H05491), JSPS Coreto-Core Program (A) Advanced Research Networks (16H00888), CREST (JPMJCR1421), and JSPS KAKENHI (18H03832). The neutron experiments were conducted at J-PARC (2019A0017, 2017L1302). The synchrotron radiation experiments were performed at the BL02B2 of SPring-8, with the approval of the Japan Synchrotron Radiation Research Institute (JASRI).

\section{Author contributions}

S.H.G., T.B., and S.F. contributed equally to this work. S.H.G. and T.B. carried out all the synthetic work. T.B., C.T., and H.U. contributed to the refinement of XRD and ND data. S.F. and A.K. performed theoretical calculations. S.H.G., K.Y., Y.X., and Y.U. contributed the conductivity measurements. I.O. and H.T. contributed the NMR measurements and analysis. Y.W. contributed to the precursor preparation. K.F. and M.Y. helped ND measurement and analyses. S.H.G., S.F., C.T., and H.K. prepared the paper and figures. H.K. designed and coordinated this study, contributed to all measurements and analyses.

\section{Competing interests}

The authors declare no competing interests. 


\section{Additional information}

Supplementary information is available for this paper at https://doi.org/10.1038/s41467020-20370-2

Correspondence and requests for materials should be addressed to C.T. or H.K.

Peer review information Nature Communications thanks Anthony West and the other, anonymous, reviewer(s) for their contribution to the peer review of this work. Peer reviewer reports are available.

Reprints and permission information is available at http://www.nature.com/reprints

Publisher's note Springer Nature remains neutral with regard to jurisdictional claims in published maps and institutional affiliations. (c) (i) Open Access This article is licensed under a Creative Commons Attribution 4.0 International License, which permits use, sharing, adaptation, distribution and reproduction in any medium or format, as long as you give appropriate credit to the original author(s) and the source, provide a link to the Creative Commons license, and indicate if changes were made. The images or other third party material in this article are included in the article's Creative Commons license, unless indicated otherwise in a credit line to the material. If material is not included in the article's Creative Commons license and your intended use is not permitted by statutory regulation or exceeds the permitted use, you will need to obtain permission directly from the copyright holder. To view a copy of this license, visit http://creativecommons.org/ licenses/by/4.0/.

(C) The Author(s) 2021 